\title{
EDUCACIÓN MÉdiCA CONTÍNUA
}

\section{MANEJO ODONTOLÓGICO DE LA PACIENTE EMBARAZADA}

\section{Hernández Rivera, Patricia}

Facultad de Odontología, Universidad de Costa Rica, San Pedro, San José, Costa Rica.

Resumen: El embarazo es un periodo en el que ocurren diversos cambios fisiológicos en la madre, para suplir el desarrollo de un nuevo ser, pero que alteran todos los sistemas corporales. Durante este periodo es fundamental que la mujer tenga un control prenatal para evitar complicaciones médicas, pero también debería tener acceso a la atención odontológica; por ello el Odontólogo debe comprender algunas generalidades propias del embarazo para poder brindar una consulta oportuna, adecuada y libre de temores. Para ello, en este artículo se explican algunas generalidades del embarazo que son relevantes para el odontólogo; además se analizan algunas patologías orales que se presentan durante este periodo y finalmente se discuten pautas para el apropiado manejo de la paciente embarazada en el consultorio odontológico.

Palabras clave: tratamiento odontológico, farmacoterapia, embarazo, gingivitis 


\title{
ODONTOLOGICAL MANAGEMENT OF THE PREGNANT PATIENT
}

\begin{abstract}
Pregnancy is a period in which many physiologic changes occur in the mother's body, to supply the developing baby being created in her womb, therefore transforming every system in her body. During this period it's essential that women get prenatal care, to prevent medical complications. It is also during this time they should have constant odontological access. Therefore odontologists should be aware of the changes happening in a woman's pregnant body to provide a timely, relevant and fear free dental treatment. This paper presents general information pertaining important facts about pregnancy and analyses some oral pathologies that could occur during this period which all dentists should be aware of. Finally we make an approach towards the understanding of the appropriate management of the pregnant woman in the dental office.
\end{abstract}

Key words: dental treatment, pregnancy, pharmacotherapy, gingivitis

\section{INTRODUCCIÓN}

Desde mediados de la década de 1970, la tasa bruta de natalidad ha descendido paulatinamente en Costa Rica; para el año 2003, fue de 17,7 por cada mil habitantes, con un total de 72938 nacimientos [1]. Paradójicamente, aún persiste un bajo porcentaje de mujeres que no reciben control prenatal, a pesar de la universalización del seguro social en nuestro país; por ejemplo, durante el año 1999, solo el $84 \%$ de las mujeres embarazadas tuvo al menos un control prenatal y de éstas, el 65\% asistió a cinco o más controles; en el caso de las adolescentes, el 75\% recibió por lo menos un control prenatal [1]. Ante esta realidad, existe la posibilidad de que un odontólogo esté atendiendo por primera vez alguna paciente embarazada, tal vez debido a una emergencia odontológica, y sea una de esas mujeres que no ha recibido atención prenatal; por lo tanto, cobra especial relevancia que el odontólogo recomiende enfáticamente la atención médica; pues esta simple acción rutinaria, podría estar disminuyendo ese porcentaje de madres que no se benefician de la atención prenatal. A la vez, el personal del área de la salud debe motivar y velar por la atención médicoodontológica de la mujer embarazada, para lograr que el $100 \%$ de las mujeres sean atendidas, con el objetivo de evitar complicaciones, prevenir algunas enfermedades y tratar padecimientos de manera oportuna y adecuada.
Este artículo tiene como objetivo explicar el manejo odontológico apropiado de la paciente embarazada, tomando en consideración los diversos cambios fisiológicos que experimenta el binomio madre-hijo durante ese periodo. Reafirmando conocimientos que en el campo de la ginecología y obstetricia son parte de la rutina diaria, pero no así en odontología; por lo tanto, es importante que el odontólogo esté familiarizado con algunas generalidades elementales que ocurren durante este periodo.

\section{GENERALIDADES DEL EMBARAZO}

El embarazo constituye un periodo de 40 a 42 semanas, el cual se divide en tres trimestres o en tres intervalos de 14 semanas [2], durante los cuales ocurre una serie de transformaciones como consecuencia del aumento en las hormonas sexuales femeninas, principalmente estrógenos y progesterona. Esos cambios son fundamentales para que la madre gestante, pueda abastecer la demanda por suplementos nutritivos y por el espacio que el feto requiere para su desarrollo y madurez; a su vez, preparan a la madre para la labor de parto $[3,4]$. 


\section{Sistema cardiovascular y hematológico}

Durante el embarazo ocurren cambios hematológicos que es importante que el odontólogo tratante comprenda. Entre los más relevantes, figura un aumento en la volemia, que oscila entre el 40 y el 50\%, debido al incremento en la cantidad de plasma, eritrocitos y células blancas. Esto es trascendental, pues ayuda a mejorar el intercambio gaseoso y de nutrientes entre la madre y el feto; además, es una preparación anticipada a la pérdida de sangre que ocurrirá durante el parto $[3,5,6,7,8,9]$. Sin embargo, el plasma se incrementa en mayor proporción y más tempranamente que el resto de los elementos, lo que provoca una "anemia fisiológica", por hemodilución. Por lo tanto, al interpretar un hemograma en una mujer embarazada se deben considerar parámetros menores a los normales $[3,5,6,7,9,10,11]$.

Como consecuencia de ese aumento del volumen sanguíneo, se eleva la frecuencia cardiaca entre 10 a 20 latidos por minuto. De igual manera, se incrementa el volumen sanguíneo por latido; lo cual ayuda a suplir la irrigación sanguínea en el útero y en las extremidades [3, 4]. Por lo tanto, cuando el odontólogo determina los signos vitales durante la primera consulta o previo a un procedimiento, es normal que al tomar el pulso en una mujer embarazada, lo encuentre ligeramente aumentado. Además, el cambio en la volemia también podría generar un soplo fisiológico, el cual no requiere tratamiento ni profilaxis antibiótica, pues se resuelve después del parto $[3,5,11,12$, 13].

Otro hallazgo que no debe alarmar al odontólogo, es la disminución en la presión arterial; pues una lectura promedio de 105/60 mm de $\mathrm{Hg}$, se considera normal durante el segundo trimestre [4]. Este cambio en la presión arterial se debe a la disminución en la resistencia vascular, por el efecto vasodilatador de la progesterona [3, $4,10,11]$. Sin embargo, luego de la semana 28 se normaliza paulatinamente $[9,13]$. No obstante, si se aumenta a más de los parámetros normales, es un signo de alerta que requiere control médico; debido a que la paciente pudiese estar presentando una hipertensión inducida por el embarazo y el consiguiente riesgo de sufrir otras complicaciones como la preeclampsia $[5,10]$.
Una alteración de relevancia para el odontólogo es el estado de "hipercoagulación" debido al aumento en la mayoría de los factores de coagulación, excepto los factores XI y XIII que disminuyen [3, 7, 8, 10, 11, 13]. Esta condición sumada a la disminución en el flujo sanguíneo en miembros inferiores, eleva el riesgo de sufrir tromboembolismo durante el embarazo; en cuyo caso la paciente recibirá terapia anticoagulante, generalmente con Heparina. Por lo tanto, dependiendo del tratamiento dental que requiera la paciente, este deberá hacerse bajo supervisión médica $[3,8,11,13]$.

\section{Sistema Respiratorio}

También se debe tener presente que la paciente embarazada podría presentar una frecuencia respiratoria elevada, pues hiperventilará como mecanismo compensatorio, para suplir el incremento en el consumo de oxígeno y la disminución en la capacidad respiratoria, como consecuencia de la elevación del diafragma, secundaria al aumento en el tamaño del útero $[3,5,8,9,10,11,13]$. Sin embargo, a pesar de estos mecanismos, hay riesgo de que la mujer sufra de hipoxia y disnea. Por lo tanto, hay que evitar colocar a la paciente en posición supina en el sillón dental, como se explicará más adelante $[8,10,11,14]$. Además, el incremento en los estrógenos causa edema en la mucosa de la vía aérea superior, congestión nasal y rinitis; lo cual incrementa el riesgo de epistaxis e infecciones respiratorias $[3,8,10,11,12,13]$. Estas complicaciones dificultan la respiración nasal, lo que incrementa la respiración bucal causando xerostomía, lo que aumenta el riesgo de caries [12].

\section{Sistema gastrointestinal: Náuseas y vómitos}

Las náuseas y los vómitos son síntomas que aquejan aproximadamente al $66 \%$ de las mujeres embarazadas durante el primer trimestre y posteriormente van disminuyendo al avanzar el tiempo de gestación. Sin embargo, hay un 1\% que continúa sufriendo estos malestares gástricos a lo largo de todo el embarazo, lo que se denomina hiperémesis gravídica [3].

Estos problemas gastrointestinales se deben a múltiples causas, entre las cuales está el retraso en el vaciamiento gástrico, la hipersalivación, la disminución en el tono muscular del esfínter esofágico y los cambios en el sentido del gusto y el olfato, que se manifiestan más durante las mañanas $[5,9,12]$. Por ello, el odontólogo debe evitar programar citas matutinas, pedirle a la paciente que no ingiera cítricos ni alimentos

Revista electrónica publicada por el Departamento de Farmacología de la Escuela de Medicina de la Universidad de Costa Rica, 2060 San José, Costa Rica. ${ }^{\circledR}$ All rights reserved. Licensed under a Creative Commons Unported License. 
grasosos, pues retrasan el vaciamiento gástrico. Además, se debe colocar a la paciente en posición semisupina $[3,4,8,13]$. Es fundamental informarle a la paciente que las múltiples emesis podrían erosionar el esmalte dental, principalmente en la superficie palatina de los dientes anteriores; debido al contenido ácido del vómito. Por lo tanto, se le debe explicar que inmediatamente después de la emesis no se cepille los dientes, pues ese ambiente ácido favorece la desmineralización del esmalte, que es incrementada por la acción del cepillado; por el contrario, se recomienda que se enjuague con una solución de una cucharadita de bicarbonato de sodio en una taza de agua, para neutralizar el pH ácido. También se debe recomendar que cepille sus dientes por lo menos dos veces al día con crema dental con flúor para favorecer la remineralización $[6,15,16]$.

\section{PATOLOGÍAS ORALES FRECUENTES DURANTE EL EMBARAZO}

\section{Gingivitis y Periodontitis}

La gingivitis y la enfermedad periodontal son patologías orales frecuentes en la población general, cuya prevalencia es mayor en las mujeres embarazadas [16]. Sin embargo, debido a que no existen estadísticas nacionales, se recurrió a datos del Departamento de Salud del Estado de Nueva York, EEUU, para ilustrar el problema; cuya estadística indica que más del 30\% de las mujeres embarazadas sufren de enfermedad periodontal y confirma que del 37 al $46 \%$ de las mujeres en edad reproductiva también sufren de esta enfermedad [2]. Esta información reafirma el hecho de que la enfermedad periodontal constituye un problema de salud pública, cuya prevalencia debe investigarse en nuestro país, pues el problema está siendo soslayado; adicionalmente, al tratarse de una patología con síntomas poco perceptibles, y con la creencia infundada de que su tratamiento es muy costoso, provoca que la mayoría de los casos no se traten y puedan evolucionar a condiciones más severas que si requieren un tratamiento más delicado. Al respecto se ha cuantificado que las enfermedades orales representan el cuarto padecimiento más caro de tratar, en la mayoría de los países industrializados [17]. En consecuencia, las campañas sobre higiene oral y estilos de vida saludables son fundamentales como parte de las estrategias para disminuir estas patologías.
La razón por la cual la enfermedad periodontal y la gingivitis son frecuentes durante el periodo de gestación se debe, principalmente, a la falta de higiene oral acompañado del incremento en la cantidad de estrógenos y progesterona [16, 18]. Pues, el aumento de estas hormonas, promueve la permeabilidad capilar y altera el tejido conectivo de la encía, lo que favorece la inflamación gingival; también, hay una disminución en la respuesta inmunológica a las bacterias. Estas variables favorecen que la mujer embarazada padezca de "gingivitis del embarazo", la cual se caracteriza por enrojecimiento, inflamación y sangrado principalmente en la encía marginal y papilar. Por lo tanto, es fundamental brindarles a las mujeres embarazadas herramientas y estrategias para el control de placa bacteriana $[3,16,18]$.

Por otro lado, la enfermedad periodontal es una infección crónica causada por bacterias, principalmente Gram negativas y anaerobias, que colonizan los nichos subgingivales [19]. Asimismo, las endotoxinas bacterianas activan el sistema inmunológico del hospedero liberando mediadores inflamatorios, como prostaglandinas, interleuquinas y factor de necrosis tumoral, entre otras citoquinas. Estas sustancias generan la destrucción del ligamento periodontal y el hueso alveolar, lo que causa la pérdida del sistema de soporte dental y a futuro, si la paciente no recibe un tratamiento adecuado, podría perder piezas dentales $[19,20,21,22]$; lo que tal vez hace eco de ese refrán popular, que dice: "un embarazo, un diente", que podría ser real si no existe el consabido tratamiento de la enfermedad periodontal.

Otros datos científicos que son importantes a considerar en este contexto, es la propuesta de que esos mediadores inflamatorios generados en la enfermedad periodontal activan anticipadamente las contracciones uterinas y la dilatación cervical [19, 20, 21, 22, 23]; por lo que se relacionan como un factor de riesgo para sufrir un parto de pretérmino, esto es, antes de las 37 semanas de gestación, o bien, aumentan el riesgo de bajo peso al nacer (menos de 2500g) [20, 23]. Estas situaciones generan complicaciones que incrementan la morbilidad y la mortalidad infantil, acarreando un alto coste hospitalario y una problemática psicológica en el seno familiar [22].

En conexión con lo anterior, se ha documentado que además de la enfermedad periodontal, hay múltiples factores que influyen en el riesgo de sufrir un parto de pretérmino y de dar a luz un niño con bajo peso, como son: la edad de la 
madre, cuando es menor de 17 años o mayor de 34 [20]; bajo nivel socioeconómico, lo cual se asocia al escaso control prenatal [20]; malos hábitos de la madre como el fumado, la ingesta de bebidas alcohólicas y otras drogas [20, 23]; así como la presencia de infecciones genitourinarias, malnutrición, baja ganancia de peso de la madre, preeclampsia o desórdenes en la coagulación; embarazos múltiples o cuando hay ruptura prematura de membranas [20], cuando muchos de estos factores se juntan es posible que también se sume una higiene oral deficiente, lo que vuelve a colocar en el tapete la necesidad imperante de insistir en las medidas de prevención y en el posible aporte que pueda brindar el odontólogo.

La compleja red multicausal del bajo peso al nacer y del parto pretérmino, dificulta sopesar la importancia individual de cada uno de los factores involucrados, especialmente de aquellos cuyo impacto puede ser indirecto, como es el caso de la enfermedad periodontal. No obstante, en diversos estudios, tipo meta-análisis, se ha encontrado que la mayoría de las investigaciones incriminan a la enfermedad periodontal como un factor de riesgo, aunque concluyen que no existe evidencia científica contundente que vincule estas patologías, pues la mayoría de los estudios analizan muestras pequeñas muy homogéneas 0 utilizan diferentes variables para evaluar la presencia de enfermedad periodontal, lo que complica la interpretación de los datos $[18,19,21$, 23]. Sin embargo, en un estudio realizado en Brasil, lograron determinar que las mujeres con periodontitis tenían 3.5 veces más de riesgo de dar a luz un niño con bajo peso; aunque, el grupo de mujeres con periodontitis también tenía otros factores como el fumado, peso anormal y la falta de control prenatal, los cuales igualmente se asocian con esta problemática del nacimiento [24].

Ante una evidencia científica poco categórica, la Academia Americana de Periodontología recomienda que las mujeres embarazadas y las que lo planean, reciban una evaluación periodontal y tratamiento odontológico para disminuir focos infecciosos e instrucciones de higiene oral, lo cual beneficia la salud oral de la madre y a su vez, disminuye la probabilidad de transmisión de microorganismos cariogénicos al niño $[16,25,26]$.

\section{Caries}

En la cavidad oral es importante destacar que ocurre un cambio importante en la composición salival, pues se disminuye el $\mathrm{pH}$ y el contenido de sodio; a su vez se incrementa el potasio, las proteínas y los niveles de estrógeno. Estos últimos exacerban la descamación de la mucosa oral y con ello, crean un ambiente propicio para la proliferación bacteriana, y por ende, aumenta el riesgo de caries [3].

Adicionalmente, algunas mujeres descuidan la higiene oral e incrementan la frecuencia de ingesta de alimentos con alto contenido de carbohidratos y azúcares; lo cual activa el metabolismo microbiano de esos carbohidratos con la consiguiente generación de radicales ácidos que disminuyen el $\mathrm{pH}$ oral, lo que propicia la desmineralización de los tejidos dentales desarrollando lesiones cariosas $[5,6,15,16]$.

Por lo tanto, es fundamental explicarle a la paciente que evite "comer entre comidas" alimentos ricos en azúcares o bebidas carbonatadas y enseñarle el correcto uso del hilo dental y el cepillado para que puedan tener un mejor control de la biopelícula dental. Además, se le debe recomendar el uso de crema dental con flúor y dependiendo del riesgo de caries se le puede aconsejar enjuagues con clorhexidina e inclusive que mastique de cuatro a cinco veces al día goma de mascar con xilitol; pues es un azúcar no fermentable que inhibe el crecimiento bacteriano y disminuye la transmisión de Streptococcus mutans al niño [2, 15, 16, 27].

Además, el odontólogo debe tratar las caries dentales eliminando el tejido afectado y posteriormente, restaurar en la medida de lo posible con materiales definitivos $[2,16]$; pues cuando el niño nazca algunas madres cancelan sus citas por falta de tiempo o en el peor de los escenarios pierden el seguro médico-odontológico, lo cual es una realidad en nuestro país. También es importante brindarle tratamiento a aquellas piezas dentales que les causan dolor, pues la mujer embarazada podría abusar del uso de analgésicos de venta libre [2].

\section{Tumor del embarazo (Granuloma piógeno)}

El tumor del embarazo, granuloma gravidum, epulis gravidarum, comúnmente denominado como granuloma piógeno, aunque este último es un término incorrecto, pues no produce pus como lo indica el vocablo "piógeno" [28]. Clínicamente se observa como una masa exofítica indolora, suave a la palpación, de coloración rojo brillante o azulado, que sangra con 
facilidad; usualmente se presenta en alguna papila vestibular y pude llegar a medir más de 2 centímetros. Esta patología es más frecuente durante el segundo trimestre del embarazo y se debe al efecto concomitante entre el aumento en las hormonas sexuales femeninas e irritantes gingivales, como el cálculo o la biopelícula dental [3, 6, 12, 16, 28, 29] (ver figura 1).

Figura 1. Granuloma gravídico

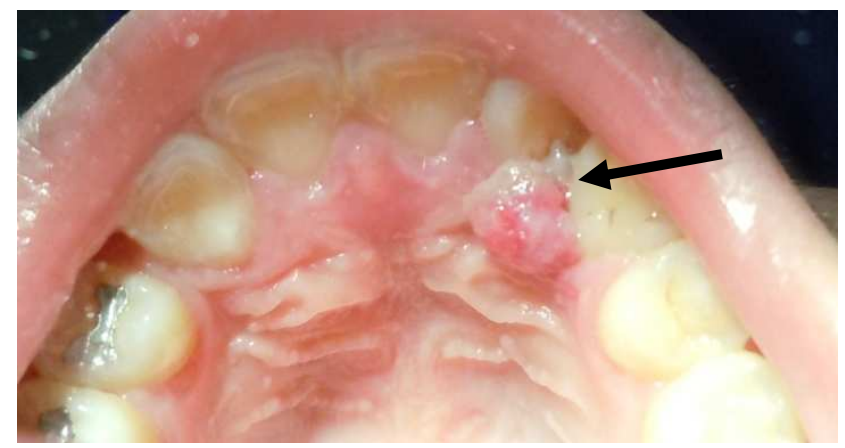

*Paciente en el tercer trimestre de embarazo, la lesión involucionó durante el postparto.

*Fuente: Cortesía Dr. Jairo Carvajal Carvajal.

Las lesiones pequeñas pueden mejorar corrigiendo la higiene oral y utilizando enjuagues con clorhexidina; no obstante, la mayoría involucionan después del parto. En el caso de las lesiones de mayor tamaño pueden dificultar la higiene oral o interferir con la masticación y requieren de una escisión quirúrgica $[6,12,16]$.

\section{Movilidad dental}

La movilidad dental es un signo de la enfermedad periodontal, que ocurre por la pérdida de inserción del sistema de soporte del diente. En las mujeres embarazadas se incrementa aún más debido a la condición gingival propia del embarazo y al cambio en la mineralización de la lámina dura. En los casos donde no existe un problema periodontal, la movilidad se revierte después del parto $[6,12,15,16]$.

\section{TRATAMIENTOS ODONTOLÓGICOS}

\section{Según trimestre de gestación}

La consulta odontológica de todo paciente, es fundamental que inicie con una historia médico-dental completa y detallada; en el caso de las mujeres se les debe preguntar la fecha de la última menstruación, lo cual podría identificar un posible embarazo. En caso de estar confirmado el embarazo, se le debe indagar el número de semanas que tiene, el nombre del médico tratante para poder realizar interconsultas, si padece de alguna patología sistémica y la historia de embarazos anteriores [6].

En la primera parte del primer trimestre ocurre la fertilización y la implantación del embrión y en la segunda parte ocurre la organogénesis; la cual se caracteriza por una alta actividad mitótica y por ello, es el periodo de mayor riesgo teratogénico $[2,6,7]$. Además, durante este trimestre existe mayor riesgo de abortos y la mujer presenta mayores síntomas gastrointestinales que se pueden exacerbar durante la consulta odontológica. Por lo tanto, durante este trimestre se recomienda brindar asesoría sobre hábitos de higiene oral y realizar tratamientos de emergencia en caso de dolor y/o infección aguda. Es aconsejable postergar los tratamientos electivos para después del parto $[2,6,15,30]$.

El segundo trimestre es el más seguro para realizar procedimientos odontológicos, pues en este lapso ya finalizó la organogénesis y el feto se encuentra en crecimiento; por lo que el riesgo teratógenico es menor. De manera que en este periodo es ideal realizar tratamientos periodontales como raspados y alisados radiculares, tratamientos restaurativos para eliminar procesos cariosos e inclusive se pueden realizar exodoncias $[2,6,15,30]$.

Las exodoncias quizás son los procedimientos que representan mayor temor; aunque si el beneficio de este tratamiento es mayor que el riesgo y si se realizan apropiadamente, no generan efectos negativos en el binomio madre-hijo. Lo cual fue comprobado por un grupo de investigadores que evaluaron los signos vitales de la madre y el feto, durante la realización de una exodoncia en 60 mujeres embarazadas agrupadas según edad gestacional. La conclusión fue que no había cambios relevantes ni significativos en los signos vitales medidos en ningún trimestre de embarazo [31].

Durante el tercer trimestre la mujer siente mayores incomodidades debido al aumento en el

Revista electrónica publicada por el Departamento de Farmacología de la Escuela de Medicina de la Universidad de Costa Rica, 2060 San José, Costa Rica. ${ }^{\circledR}$ All rights reserved. Licensed under a Creative Commons Unported License. 
volumen del útero, por lo tanto es importante que la mayoría de los tratamientos se hayan realizado durante el segundo trimestre. Sin embargo, cualquier emergencia debe ser resuelta inmediatamente y se pueden continuar con los tratamientos para eliminar focos cariosos y enfermedad periodontal; para ello se deben programar citas cortas y cuidar la posición en el sillón dental $[2,6,15]$.

\section{Posición en el sillón dental}

En el ámbito odontológico es fundamental tener presente que a partir del segundo trimestre, algunas pacientes podrían presentar el Síndrome de hipotensión supina, el cual ocurre cuando la paciente se encuentra en posición supina y el peso del útero grávido comprime la vena cava inferior $[3,10,11,13,14,16,30]$. Esto provoca una disminución en el retorno venoso hacia el corazón, lo que estimula a los barorreceptores como mecanismo compensatorio para mantener el volumen sanguíneo y como consecuencia, la paciente va a presentar: náuseas, vértigo, hipotensión, palidez, sudoración, taquicardia, síncope y en casos severos, pérdida de conciencia e inclusive convulsiones $[3,10,11,14,30]$. Además, en esa posición, se oprime la aorta lo que causa una disminución en la irrigación hacia las arterias iliacas $y$ en consecuencia afecta el área uteroplacentaria $[10,11,14,30]$. Esta complicación se evita colocando una almohada debajo de la cadera derecha, con el objetivo de elevarla aproximadamente de 10 a $12 \mathrm{~cm}$; de manera que la paciente quede en posición decúbito supino lateral izquierdo, tal como se muestra en la figura 2. [3, 8, 10, 11, 12, 13, 14, 16, 30] (Ver figura 2).

\section{Selección de fármacos durante el embarazo}

Durante el embarazo tanto la mujer como el odontólogo tratante se sienten temerosos en cuanto al uso de medicamentos, pues dependiendo de la edad gestacional, dosis, frecuencia, duración y vía de administración en el que se utilicen e inclusive factores genéticos, podrían ser factores que predispongan algún efecto teratogénico $[4,32,33,34]$. Por droga teratogénica se entiende a aquella sustancia que provoca una alteración funcional o estructural en algún órgano durante el desarrollo embrionario o fetal. Por lo tanto, se debe evaluar minuciosamente el empleo de cualquier medicamento, pues la mayoría de las drogas atraviesan la placenta, no obstante no se debe esquivar su empleo, ya que deben tratarse todas aquellas enfermedades que pongan en riesgo la salud de la madre y por ende la del hijo $[7,34]$.

\section{Figura 2: Correcta posición (decúbito supino lateral izquierdo) de una paciente embarazada en el sillón dental.}

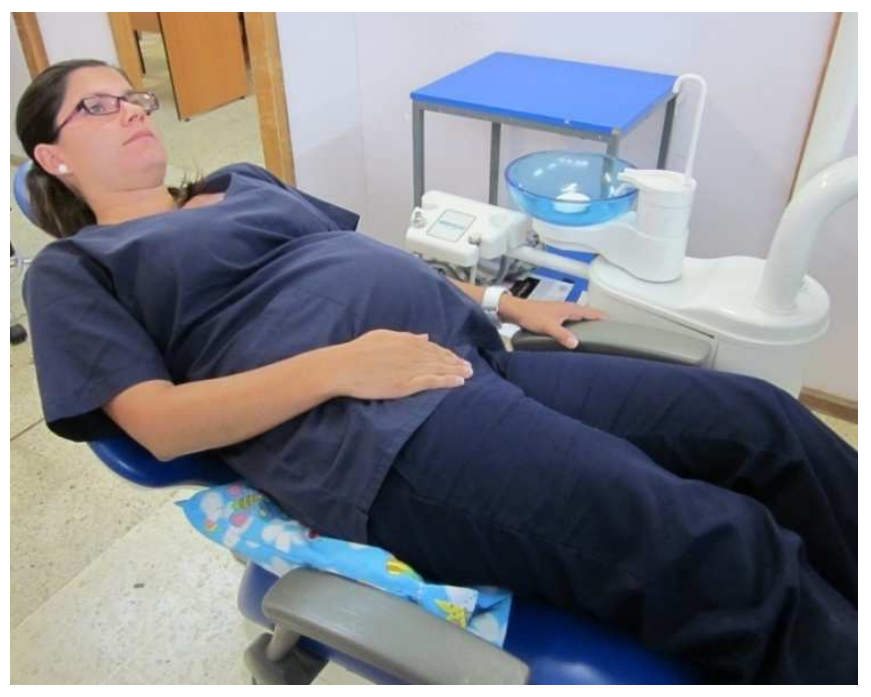

*Paciente autorizó la publicación de la fotografía.

Por esta razón, en EEUU la Food and Drug Administration (FDA) ha clasificado las diversas drogas según el potencial para producir un daño teratógenico cuando se emplean en dosis clínicas, basado en múltiples investigaciones que se han desarrollado en el mundo [7, 14, 34, 35, 36]. Sin embargo, esta organización está modificando la legislatura para cambiar la nomenclatura de letras por una leyenda; en la cual se explique detalladamente los posibles riesgos según los estudios. De manera que la información pueda ser mejor analizada para tomar la decisión del empleo de una droga, según el riesgo beneficio [36]. No obstante es importante conocer la clasificación en letras y conocer el significado, la cual se detalla en el cuadro 1 con algunos ejemplos de medicamentos utilizados en Odontología. 


\section{Cuadro 1: Clasificación de medicamentos comúnmente utilizados en Odontología, según el riesgo teratogénico estipulado por la FDA}

\begin{tabular}{|c|c|c|}
\hline Categoría & Descripción & Ejemplo \\
\hline $\mathbf{A}$ & $\begin{array}{l}\text { Existen estudios adecuados y bien controlados en mujeres } \\
\text { embarazadas, los cuales no han demostrado algún riesgo fetal. } \\
\text { La posibilidad de riesgo es remota. }\end{array}$ & \\
\hline B & $\begin{array}{l}\text { Los estudios en animales no han demostrado riesgo fetal, y no } \\
\text { hay estudios bien controlados en mujeres embarazadas. } \\
\text { También cuando los estudios en animales mostraron un efecto } \\
\text { adverso, pero no se confirma un riesgo fetal en el primer } \\
\text { trimestre en estudios bien controlados en mujeres } \\
\text { embarazadas. }\end{array}$ & $\begin{array}{l}\text { Lidocaina, Acetaminofén } \\
\text { AINES (durante el } 1 \text { y } 2 \text { trimestre) } \\
\text { Amoxicilina, Clorhexidina }\end{array}$ \\
\hline C & $\begin{array}{l}\text { Los estudios en animales demuestran daño fetal y no existen } \\
\text { estudios adecuados bien controlados en humanos. También } \\
\text { cuando no existen estudios en animales ni en humanos. Las } \\
\text { drogas se suministran si el beneficio obtenido es mayor que el } \\
\text { riesgo potencial de daño fetal. }\end{array}$ & $\begin{array}{l}\text { Mepivacaina, Articaina } \\
\text { Ácido acetil salicílico } \\
\text { Codeina, COX-2 }\end{array}$ \\
\hline D & $\begin{array}{l}\text { Existe evidencia científica producto de investigaciones y } \\
\text { estudios en humanos que demuestran riesgo fetal en } \\
\text { humanos, su uso se justifica solo en caso de una enfermedad } \\
\text { que amenace la vida de la paciente, por lo que se considera } \\
\text { que el beneficio potencial en mujeres embarazadas es } \\
\text { aceptable a pesar del riesgo. }\end{array}$ & $\begin{array}{l}\text { AINES (durante el } 3 \text { trimestre) } \\
\text { Tetraciclina }\end{array}$ \\
\hline $\mathbf{X}$ & $\begin{array}{l}\text { Los estudios en animales y en humanos demuestran } \\
\text { anormalidades o cuando existe evidencia producto de } \\
\text { investigaciones y/o la experiencia que demuestran daño fetal. } \\
\text { El riesgo de utilizar este tipo de drogas sobrepasa el beneficio } \\
\text { obtenido, por lo que está contraindicada en mujeres } \\
\text { embarazadas o en mujeres que puedan quedar embarazadas. }\end{array}$ & \\
\hline
\end{tabular}

Información adaptada de la FDA [36].

distribución de la droga pues hay un mayor volumen sanguíneo y la eliminación de las drogas se incrementa debido al aumento en la frecuencia de filtración glomerular [3, 4, 5 6, 14, 32, 33].

Por otro lado, las transformaciones sistémicas que ocurren durante la gestación influyen en la farmacocinética de los medicamentos; pues la absorción es más lenta debido a la menor producción de ácido estomacal y al retardo en el vaciamiento gástrico [5, 14, 32]. A su vez, hay una mayor

\section{Anestésicos locales}

El odontólogo debe comprender el uso de los anestésicos locales en la paciente embarazada, de manera que los procedimientos dentales los realice de forma indolora, sin generar ansiedad ni temores en la paciente.

Revista electrónica publicada por el Departamento de Farmacología de la Escuela de Medicina de la Universidad de Costa Rica, 2060 San José, Costa Rica. ${ }^{\circledR}$ All rights reserved. Licensed under a Creative Commons Unported License. 
En general, los anestésicos locales atraviesan la barrera placentaria, no obstante su utilización durante el cualquier trimestre del embarazo es segura y no teratogénica $[7,37]$. La lidocaina es el anestésico de primera elección debido a que la FDA lo cataloga como B y en el caso de la Articaina y la Mepivacaina se clasifica como C, por la falta de estudios en animales [5, 7, 38,].

Sin embargo, a pesar de ser drogas consideradas como seguras para el feto, deben utilizarse con cautela y limitar la dosis; pues la cantidad de anestésico libre en sangre se incrementa debido a la disminución en la proteína sérica, alfa glicoproteína ácida. $[3,37,38]$. Otro aspecto a considerar es el uso de la epinefrina, una sustancia equivalente a la adrenalina, por lo tanto no representa una contraindicación y la FDA la registra como $C[3,5]$. No obstante, hay que restringir la dosis a menos de 0,04 mg por cita y evitar infiltraciones intravasculares; pues cuando inadvertidamente se infiltra dentro de un vaso hay una leve disminución en el flujo sanguíneo uterino, similar a lo que ocurre durante una contracción [3, $5,6,37]$.

\section{Analgésicos}

Es fundamental brindarle a la paciente embarazada una adecuada terapia analgésica y tratamientos oportunos que le eliminen las dolencias y así evitar que la paciente se sobre medique con drogas de venta libre o productos denominados como "naturales", los cuales podrían aumentar el riesgo de complicaciones por un uso excesivo.

El analgésico de elección durante todo el periodo gestacional es el Acetaminofén, debido a que los estudios científicos no han relacionado el uso de este medicamento con daños congénitos, por lo que la FDA lo clasifica como B [3, 5, 11]. Sin embargo, en altas dosis puede causar anemia, metahemoglobinemia y toxicidad hepática; por lo tanto no se debe sobrepasar la dosis máxima, la cual es de 4 gramos al día [3, 35, 39].

En el caso de los anti-inflamatorios no esteroideos (AINES) se ha determinado que constriñen o causan el cierre prematuro del ducto arterioso, lo cual provoca hipertensión pulmonar primaria, problemas en la respiración y anormalidades en la hemostasia. También retardan la labor de parto, pues inhiben las prostaglandinas, las cuales actúan sobre el músculo liso. Por lo tanto, la FDA los ha clasificado como D durante el tercer trimestre y como B durante el primer y segundo; razón por la cual debe recetarse la menor dosis efectiva por un máximo de 24 a 72 horas y evitar utilizarlos 6 u 8 semanas antes del parto [3, 7, 8, 11, 35].

El ácido acetil salicílico se cataloga como C, pero cuando se utiliza en altas dosis durante el tercer trimestre cambia su clasificación a D. Se ha relacionado con hemorragias cuando las madres ingieren altas dosis en los cinco días previos al parto; no obstante, en dosis diarias bajas no han ocasionado daños fetales. Por lo tanto, debe utilizarse con cautela y evitarse durante el tercer trimestre, pues también puede causar el cierre prematuro del ducto arterioso y retrasar la labor de parto $[7,8,11,35,39]$.

Los analgésicos COX-2 se clasifican como $\mathrm{C}$ y también causan el cierre prematuro del ducto arterioso $[8,37,40]$.

La codeína se clasifica como $\mathrm{C}$, aunque es bastante segura, pues se han realizado estudios en animales y han demostrado que en dosis tóxicas ocurre una disminución en el peso fetal, lo cual no sucede en dosis normales $[5,11]$.

\section{Antimicrobianos}

En la paciente embarazada hay un cambio en la actividad inmunológica, pues hay una disminución en la inmunidad mediada por células, para evitar que el feto sea reconocido como extraño y destruido $[5,13,14]$. Sin embargo, esa "inmunosupresión" provoca que las infecciones evolucionen rápidamente e inclusive se diseminen a espacios profundos, que podrían comprometer la vía aérea de la paciente, lo cual es una complicación que pone en riesgo la vida del binomio madre-hijo [13]. Por lo tanto, es vital el tratamiento oportuno de cualquier infección que se presente durante este periodo.

Los antibióticos Beta-lactámicos son la primera elección, por tener un alto grado de seguridad a pesar de que atraviesan la placenta $[3,7,33]$. Inclusive, la penicilina se ha utilizado desde la década de los años 40 y no ha demostrado incrementar la incidencia de malformaciones congénitas, por lo que se puede utilizar en cualquier trimestre del embarazo $[8,35]$. En el caso de la Amoxicilina, los estudios en animales no han 
revelado daños fetales, aunque se han utilizado dosis hasta diez veces las empleadas en humanos; por lo que la FDA lo ha catalogado como B. La combinación de amoxicilina y ácido clavulánico tampoco ha generado alteraciones congénitas y también se ha clasificado como B [39].

Las Cefalosporinas son antibióticos seguros, ya que los estudios realizados en animales no han revelado el desarrollo de efectos adversos en los fetos, aún cuando los científicos utilizaron dosis 60 veces a la recomendada para el humano. Asimismo, se han efectuado estudios retrospectivos, dándole seguimiento a las mujeres embarazadas que han tenido que ingerir este antibiótico, los cuales no han evidenciado que este produzca alteraciones fetales; por lo tanto la FDA lo registra como $\mathrm{B}[8,39,33]$.

La familia de los Macrólidos, a la cual pertenecen la Eritromicina, la Claritromicina y la Azitromicina son los antibióticos ideales, a excepción de la Claritromicina, cuando la paciente es alérgica a las penicilinas o en casos de resistencia bacteriana. La Azitromicina y la Eritromicina se clasifican como B, aunque se debe evitar el uso del Estolato de eritromicina debido a que causa hepatitis colestática en las madres gestantes [8, 33, 35]. La Claritromicina se cataloga como C, pues en mujeres embarazadas se han descubierto casos de malformaciones congénitas y abortos espontáneos, los cuales a pesar de no ser estadísticamente significativos, se recomienda valorar el riesgo-beneficio en la embarazada; por lo que se necesitan más estudios que esclarezcan si existe un riesgo real al emplearlos durante el embarazo [39].

En el caso de la Clindamicina, es una Licomicina que inhibe la biosíntesis de proteínas bacterianas y se cataloga como B [33]. Los estudios realizados en animales no han demostrado que la droga produzca alteraciones fetales $y$ en investigaciones en mujeres embarazadas, tampoco incrementa las incidencias de malformaciones; por lo que se puede administrar durante el embarazo [39] Sin embargo, debe emplearse solamente en casos muy específicos debido a que un efecto indeseable de este fármaco es la diarrea crónica y la colitis seudomembranosa causada por la toxina del Clostridium difficile [33, 4, 40].
El Metronidazol es bactericida, amebicida y tricomonicida que se ha registrado como B; debido a que los múltiples análisis de estudios científicos no revelan que este medicamento incremente las incidencias de malformaciones fetales, aunque existen casos documentados de labio-paladar hendido, por lo que es preferible evitarlo durante el primer trimestre $[8,12,33,39,40]$.

La familia de las Tetraciclinas se clasifica como D, porque estos antibióticos tienen moléculas, las cuales quelan el ortofosfato de calcio, el cual se incorpora durante la mineralización de los huesos y los dientes, lo que inhibe el crecimiento óseo y produce pigmentaciones dentales $[3,7,11,33,35,40]$. Por lo tanto, este tipo de antibiótico está contraindicado durante el embarazo, pues la evidencia científica indica que hay un riesgo relativo del $50 \%$ de que produzca daños en huesos y en dientes [39].

La Clorhexidina es catalogada como B, según la FDA y se recomienda utilizarla en forma de enjuagatorios que no contengan alcohol, para prevenir la gingivitis gestacional $[3,12,15,16]$.

\section{Toma de radiografías durante el embarazo}

Los rayos $\mathrm{x}$ son una fuente de energía electromagnética que tienen la capacidad de ionizar la materia que atraviesan, lo cual puede generar muerte celular, efectos teratogénicos, carcinogénesis o mutagénesis; dependiendo del tipo de tejido irradiado, tiempo de exposición, frecuencia y en el caso de las mujeres embarazadas también influye la edad gestacional $[3,41]$. Sin embargo, está documentado que en exposiciones menores a los 5 rad (lo que equivale a 0,05 Gy) no hay un incremento en los abortos espontáneos ni en los daños congénitos. Inclusive cuando se toma un juego completo de 18 radiografías periapicales de velocidad $\mathrm{D}$ y se utiliza el delantal de plomo, la radiación que recibe el feto es de 0,0000001 Gy y cuando se realiza una radiografía panorámica sería de 0,00001 Gy; lo cual es inferior a la radiación promedio que recibe una persona en un jardín durante 2,5 horas en Estados Unidos [2, 3, 6].

La toma de radiografías dentales durante el embarazo es un medio diagnóstico seguro, ya que 
el haz de rayos X se ubica en el área de cabeza y cuello. No obstante, es fundamental utilizar películas de alta velocidad, colocarle el delantal de plomo a la paciente, usar colimación y emplear bajas exposiciones; así como regirse con el principio de LARA, tan bajo como sea razonablemente posible, por sus siglas en inglés. Además, es preferible minimizar al máximo la realización de éstas durante el primer trimestre, debido a que es el periodo de organogénesis $[6,7$, $12,16]$. Por lo tanto, es fundamental explicarle a la paciente la importancia de la toma de radiografías como medio diagnóstico.

\section{MITOS DEL EMBARAZO}

Existen una serie de mitos acerca del embarazo, que aunque erróneos, se han pasado de generación en generación e inclusive se creen ciertos en muchos países. Por ello, el personal del área de la salud debe esclarecer esos mitos y hacer conciencia de la importancia de la atención médica-odontológica de la paciente embarazada, para evitar que situaciones que se consideran como "propias" del estado gestacional sean tratadas oportunamente por un profesional.

\section{"Hay que comer por 2"}

Popularmente se cree que durante el embarazo la mujer debe duplicar su ingesta de alimentos para poder abastecer de nutrientes y energía al feto en desarrollo. Sin embargo, en realidad la mujer embarazada solo tendría que aumentar en 300 calorías su dieta diaria y no debería ascender su peso total a más de $14 \mathrm{Kg}[2$, 5 , 9]. Para ello, hay que limitar los alimentos ricos en azúcares y grasas e incrementar las actividades físicas aeróbicas de bajo impacto, que tengan bajo riesgo de lesiones accidentales como por ejemplo caminar, nadar o hacer yoga [2]. A pesar de que la actividad física diaria disminuye las posibilidades de sufrir diabetes gestacional o un parto de pretérmino, es recomendable consultar con el médico tratante y procurar realizar los ejercicios en ambientes ventilados y mantener una adecuada hidratación [42].

\section{"Un diente por cada hijo", "El embarazo debilita los dientes"}

Otro de los mitos comunes es que las mujeres justifiquen la presencia de caries y la pérdida de piezas dentales con el embarazo; lo cual es totalmente falso. A pesar de que los cambios hormonales que ocurren durante el embarazo hacen más susceptibles a las mujeres a sufrir de gingivitis y que las náuseas y los vómitos desmineralizan el esmalte de los dientes; existen múltiples medidas preventivas para evitar que esto ocurra. Sin embargo, un efecto concomitante son los deseos de comer o "antojos" durante el periodo de gestación, los cuales normalmente son saciados con meriendas con alto contenido calórico y en algunos casos las medidas de higiene oral no son las adecuadas; lo cual genera un ambiente propicio para el desarrollo de caries $[5,27,29]$.

Además, hay madres que piensan que deben evitar la consulta odontológica, por temor a que el tratamiento le provoque algún daño a su hijo. De igual manera, hay odontólogos que prefieren postergar los tratamientos para después del parto. Sin embargo, durante el periodo del posparto las madres enfrentan un cambio de vida, pues deben suplir la alimentación y el cuidado del bebé, lo cual dificulta la asistencia a la consulta odontológica. Inclusive algunas madres de escasos recursos económicos pierden su seguro de salud, por lo que las piezas dentales con caries se mantienen activas, sin tratamiento y lamentablemente por esa ausencia de atención odontológica pierden las piezas dentales $[5,27,29]$.

Otro argumento que valida la creencia que el embarazo provoca la pérdida de piezas dentales, es que el feto toma el calcio de los dientes de la madre, para desarrollar su esqueleto y dientes. Lo cual es totalmente falso, pues el calcio contenido en los dientes es estable y no forma parte de la circulación sistémica. Aunque, sí existe un transporte activo de calcio a través de la placenta ésta necesidad se compensa con la mayor absorción de calcio en el intestino; por lo que es fundamental que la mujer ingiera aproximadamente de 1 a 1,3 g de calcio, pues si hay una deficiencia alimentaria de este mineral se reabsorberá de los huesos, aunque se recupera en el posparto [14, 29].

\section{CONCLUSIONES}

Es importante que el odontólogo pueda discernir entre los cambios fisiológicos propios del

Revista electrónica publicada por el Departamento de Farmacología de la Escuela de Medicina de la Universidad de Costa Rica, 2060 San José, Costa Rica. ${ }^{\circledR}$ All rights reserved. Licensed under a Creative Commons Unported License. 
embarazo y los que representan alguna alteración que deba ser evaluada por el médico tratante. Por otro lado, es fundamental que se lleve a cabo un examen de tejidos blandos y duros, así como una minuciosa evaluación periodontal; de manera que se puedan tratar los focos infecciosos y brindar instrucciones para mejorar la higiene oral de la paciente. De esta forma, se disminuirá las posibilidades que la madre le transmita bacterias cariogénicas a su hijo y también se podrá prevenir la gingivitis y periodontitis, lo cual beneficiará la salud de la madre y aunque, no hay evidencia contundente, podría ser que se evite un parto de pretérmino o el nacimiento de un niño con bajo peso.

Por otro lado, es trascendental recalcar que la atención odontológica durante el embarazo es segura,

\section{REFERENCIAS}

1. Rojas M, Castellanos F, Marín C, Bustamante X, Montiel H. (Ministerio de Salud, Organización Panamericana de la Salud, Organización Mundial de la Salud). Salud de las mujeres en Costa Rica: Un análisis desde la perspectiva de género. Organización Panamericana de la Salud, Organización Mundial de la Salud; 2005 Abril. http://www.ministeriodesalud.go.cr/index.php/ inicio-vigilancia-indicadores-saludms/cat view/121-vigilancia-de-la-salud/155indicadores-de-salud/157-genero/166-saluden-la-mujeres

2. New York State Department of Health. Oral Health Care during Pregnancy and Early Childhood: Practice Guideline. New York State Department of Health; August 2006. No. 0824. http://www.health.ny.gov/publications/0824.p $\underline{\mathrm{df}}$

3. Suresh L, Radfar L. Medical management update: "Pregnancy and lactation". Oral Surg Oral Med Oral Pathol Oral Radiol Endod 2004; 97(6): 672682.

4. Goodman S. Anesthesia for nonobstetric surgery in the pregnant patient. Seminars in Perinatology 2002 April; 26(2): 136-145.

5. Dellinger T, Livingston HM. Pregnancy: inclusive la toma de radiografías, solamente se deben tomar algunas consideraciones. Por el contrario, la negligencia podría generarle a la paciente el avance de infecciones que podrían poner en riesgo su salud o dolores dentales que podrían incrementar la ingesta de fármacos de venta libre. Por ello, debe analizarse en cada caso, si las radiografías son necesarias para establecer un diagnóstico certero y si se deben realizar, tomar la menor cantidad y poner en práctica las medidas preventivas para disminuir al máximo la exposición del feto a la radiación. También se debe estudiar la prescripción de medicamentos durante este periodo según el riesgo-beneficio.

Asimismo, es primordial que el personal del área de la salud esclarezca los mitos que se han generado sobre el embarazo, esto con el fin de motivar a que las pacientes reciban atención odontológica y con ello, mejorar su salud bucodental.

Physiologic Changes and Considerations for Dental Patient. Dent Clin N Am 2006; 50: 677697.

6. Rieken S, Terezhalmy GT. The pregnant and breast-feeding patient. Quintessence Int 2006; 37: 455-468.

7. Cengiz SB. The pregnant patient: Considerations for dental management and drug use. Quintessense Int 2007 March; 38(3): 133-142.

8. Turner M, Aziz SR. Management of the Pregnant Oral and Maxillofacial Patient. J Oral Maxillofac Surg 2002; 60: 1479-1488.

9. Escalante JA. Adaptación materna al embarazo. Modificaciones grávicas. En: Usandizaga JA, de la Fuente P. Editores. Tratado de Obstetricia y Ginecología. Madrid, España: McGraw Hill; 1997. p. 88-105.

10. Ueeck B, Assael LA. Perioperative Management of the female and Gravid Patient. Oral Maxillofacial Surg Clin N Am 2006; 18: 195-202.

11. Flynn TR, Susarla SM. Oral and Maxillofacial Surgery for the Pregnant Patient. Oral Maxillofacial Surg Clin N AM 2007; 19: 207-221.

12. Giglio JA, Lanni SM, Laskin DM, Giglio NW. Oral health Care for the Pregnant Patient. Journal of the Canadian Dental Association 2009 February; 75 (1): 43-48.

Revista electrónica publicada por el Departamento de Farmacología de la Escuela de Medicina de la Universidad de Costa Rica, 2060 San José, Costa Rica. ${ }^{\circledR}$ All rights reserved. Licensed under a Creative Commons Unported License. 
13. Lawrenz D, Whitley B, Helfrick J. Considerations in the management of maxillofacial infections in the pregnant patient. J Oral Maxillofac Surg 1996; 54: 474-485.

14. Chisholm CA, Ferguson JE. Physiologic and pharmacologic Factors Related to the provision of Dental Care during Pregnancy. Journal of the California Dental Association 2010; 38(9): 663671.

15. Gajendra S, Kumar J. Oral Health and Pregnancy: A review. New York State Dental Journal January 2004; 70(1): 40-44. http://www.nysdental.org/publications/archive -popup.cfm?ID=7

16. CDA Foundation. Oral Health during Pregnancy and Early Childhood: Evidence-Based Guidelines for Health Professionals. CDA Foundation; 2010 February. http://www.cdafoundation.org/Portals/0/pdfs/ poh guidelines.pdf

17. Petersen PE (World Health Organization). The World Oral Health Report. Global Oral Health Programme, World Health Organization; 2003.

18. Lachat M, AL Solnik, Nana A, Citron T. Periodontal Disease in Pregnancy Review of Evidence and Prevention Stratagies. J Perinal Nurs 2011 october-december; 25(4): 312-319.

19. Dasanayake A, Genaro S, Hendricks-Muñoz K, Chhun N. Maternal periodontal disease, pregnancy, and neonatal outcomes. MCN 2008 Januay-February; 33(1): 45-49.

20. Kawar N, Alrayyes S. Periodontitis in pregnancy: The risk of preterm labor and low birth weight. Dis Mon 2011; 57: 192-202.

21. Menezes EV, Yakoob MY, Somro T, Haws RA, Darmstadt GL, Bhutta ZA. Reducing stillbirths: prevention and management of medical disorders and infections during pregnancy. BMC Pregnancy and Child birth 2009; 9(Suppl1):S4.

22. Tarannum F, Faizuddin M, Madaiah H. Gingival crevicular fluid prostaglandin E2 level as a predictor of preterm low birth weight: a pilot investigation. J Oral Sci 2011; 53(3) 293-300.

23. Clothier B, Stringer M, Jeffcoat M. Periodontal disease and pregnancy outcomes: exposure, risk and intervention. Best Practice \& Research Clinical Obstetrics and Gynaecology 2007; 21(3) 451-466.

24. López NJ, Smith PC, Gutiérrez J. Untreated periodontitis in pregnant women may increase the risk for a low-birthweight infant. J Evid Base Dent Pract 2003; 3: 24-25.

25. American Academy of Periodontology. Statement Regarding Periodontal Management of the Pregnant Patient. J Periodontol 2004 March; 495.

26. Volpato F, Jeremias F, Spolidório D, Silva S, Valsecki Junior A, López F. Effects of Oral Enviroment Stabilization procedures on Streptococcus mutans counts in pregnant women. Braz Dent J 2001; 22(4): 280-284.

27. Fitzsimons D, Dwyer J, Palmer C, Boyd L. Nutrition and oral health guidelines for women, infants and children. Journal of the American Dietetic Association 1998 February; 98 (2) 182189.

28. Marx R, Stern D. Oral and Maxillofacial Pathology: A Rationale for Diagnosis and Treatment. Illinois, USA: Quintessence Publishing; 2003.

29. Russell SL, Mayberry LJ. Pregnancy and Oral Health: A review and recommendations to reduce gaps in practice and research. MCN 2008 January-February; 33(1): 32-37.

30. Fayans E, Stuart H, Carsten D, Ly Q, Kim H. Local Anesthetic use in the Pregnant and Postpartum Patient. Dent Clin N Am 2010; 54: 697-713.

31. Daza JA, Echalar E. Interpretación del riesgo quirúrgico de las exodoncias durante la gestación. Rev Inst Med “Sucre” 1995; LX: 121138.

32. De la Fuente P. Fármacos y embarazo. En: Usandizaga JA, de la Fuente P. Editores. Tratado de Obstetricia y Ginecología. Madrid, España: McGraw Hill; 1997. p174-179.

33. Lodi KB, Carvalho LF, Koga-Ito CY, Carvalho VA, Rocha RF. Rational use of antimicrobials in dentistry during pregnancy. Med Oral Patol Oral Cir Bucal 2009 Jan; 14(1):E15-19.

34. Center for Drug Evaluation and Research, Center for Biologics Evaluation and Research. Reviewer

Revista electrónica publicada por el Departamento de Farmacología de la Escuela de Medicina de la Universidad de Costa Rica, 2060 San José, Costa Rica. ${ }^{\circledR}$ All rights reserved. Licensed under a Creative Commons Unported License.

Contáctenos: rev.med.ucr@gmail.com. Tel: (506) 25-11 4492, Fax: 25-11-4489. 
Guidance Evaluation the Risks of Drug Exposure in Human Pregnancies; 2005 April.

http://www.fda.gov/downloads/scienceresearc h/specialtopics/womenshealthresearch/ucm13 3359.pdf

35. Benrubi GI. Urgencias Obstétricas y Ginecológicas. Puente JM, Muñoz E, Peramo B, traductores. Madrid, España: Marbán Libros SL; c2003. p445.

36. Food and Drug Administration (US). Content and Format of Labeling for Human Prescription Drug and Biological Products; Requirements for Pregnancy and Lactation Labeling. Proposed Rule. Fed Regist. 2008 May 29; 73(104): 3038130863.

http://www.regulations.gov/\#!documentDetail; D=FDA-2006-N-0515-0001

37. Turner MD, Singh F, Glickman RS. Dental Management of the Gravid Patient. New York State Dental Journal 2006 November; 72 (6) 2227.

http://www.nysdental.org/publications/archive -popup.cfm?ID=29

38. Malahmed S. Handbook of Local Anesthesia. Missouri, USA: Elsevier Mosby; 2004.

39. Romá E, García J, Poveda JL, Ferrer E. Medicamentos y Embarazo: Informes de evaluación de teratogenia en el primer trimestre de embarazo. España: Generalitat Valenciana Conselleria de Sanitat; 2007.

40. Brunton LL, Parker KL. Goodman \& Gilman Manual de farmacología terapéutica. Orizaga J, traductor. México: McGraw Hill; 2009. p1221.

41. ACOG Committee on Obstetric Practice. Guideline for Diagnostic Imaging During Pregnancy. Obstet Gynecol 2004; 104: 647-651.

42. Rayburn WF, Phelan ST. Promoting Healthy Habits in Pregnancy. Obstet Gynecol Clin N Am 2008; 35: 385-400.

\section{INFORMACION DE AUTOR:}

Hernández Rivera, Patricia

Email: patricia.hernandezrivera@ucr.ac.cr

Universidad de Costa Rica, Facultad de Odontología. San José, Costa Rica.

Odontóloga general, Máster en Administración de Instituciones Educativas. 